\title{
Social Media Posts on the Samsung Galaxy Note 7 Explosion: A Comparative Analysis of Crisis Framing and Sentiment in Three Nations
}

\author{
Seok Kang (1D, ${ }^{a}$ KyuJin Shim, ${ }^{b}$ and Jiyoun Kim ${ }^{\mathrm{c}}$ \\ aDepartment of Communication, University of Texas at San Antonio, San \\ Antonio, Texas, USA; 'Department of Culture and Communication, University of \\ Melbourne, Melbourne, Australia; 'Department of Communication, University of \\ Maryland, College Park, Maryland, USA
}

\begin{abstract}
This study explores the Samsung Galaxy Note 7 explosion crisis by analyzing posts on Twitter in three nations: the United States, Australia, and South Korea. Using the perspectives of generic frames, issue-specific frames, cross-national frames, and user sentiment on Twitter, this study analyzes 600 posts ( 200 from each nation). Results reveal that Twitter posts frequently framed the crisis using attribution, morality, and conflict frames. Posts about the explosion were more professional frame oriented than national frame oriented. Negative sentiment was dominant in Twitter posts about the explosion. Morality, corporate breakdown, and customer concerns were highly associated with negative sentiment. The results demonstrate how global users respond to a corporate crisis. Study implications and suggestions are discussed.
\end{abstract}

KEYWORDS: Samsung Galaxy Note 7 explosion; crisis framing; social media sentiment

A corporate crisis shapes the reputation of the corporation affected, public opinion regarding the corporation, and the economy of the nation where the crisis occurs (An \& Gower, 2009). Media coverage of a corporate crisis can influence corporations, governments, and stakeholders to a substantial degree. A crisis is a stage of an event at which future events can be better or worse. Such future events unfold depending on the causes, attributions, and solutions of the crisis (Coombs \& Holladay, 2004). As such, how the public views a crisis is an important factor in determining the fate of involved organizations.

CONTACT Seok Kang, PhD·E-mail: seok.kang@utsa.edu • Department of Communication, University of Texas at San Antonio, MB 2.248K, San Antonio, TX 78249, USA 
In communication research, an indispensable step toward identifying the effects of a corporate crisis is to examine how the crisis is framed in media because how media frame a corporate crisis facilitates or deteriorates publics' attitudes and behaviors toward the corporation (Coombs, 2006; Valentini \& Romenti, 2011).

In recent years, media message production and distribution have transformed in an interactive way (Hindman, 2009). Audiences readily engage with people by sharing, endorsing, or opposing posts on social media. Audiences offer opinions on issues in interactive news platforms (Diehl, Weeks, \& Gil de Zúñiga, 2016). Furthermore, as J. Kim, Brossard, Scheufele, and Xenos (2016) also discussed, the sentiment shared on social media about a crisis influences how audiences perceive the issue. Given the increasing impact of social media posts on users regarding active internalizing (viewing) and externalizing (sharing or retweeting; Diehl et al., 2016), it is crucial to investigate how message frames relate to audience sentiment, which can form public opinion.

Crisis information is disseminated faster on social media than other news channels due to users' direct posts on sites, virality, and global reach, which make the crisis's impact powerful (van der Meer \& Verhoeven, 2013). When a massive earthquake and tsunami caused a nuclear accident in Japan in 2011, one particular article about the crisis was the most shared story on Facebook that year (Facebook, 2011). For this reason, researchers are concerned with how issues, frames, opinions, and sentiment on social media influence public perceptions of a crisis at an international level (Hajdu, Pápay, Szántó, \& Tóth, 2018). Even though several researchers have focused on social media content related to crises (e.g., Ceron, 2015; J. Kim et al., 2016) and users' issuesharing intentions (Khuntia, Sun, \& Yim, 2016), scant research has been conducted on corporate crisis framing and on relating framing to sentiment in an international context. Hence, using a recent global corporate crisis as a case, this study seeks to (a) track which frames frequently occurred in social media posts; (b) explore online sentiment toward the brand, product, and crisis; and (c) demonstrate the relationship between message frames and audience sentiment.

The current study conducted a social media content analysis of the Samsung Galaxy Note 7 explosion crisis, which caused serious safety 
concerns (e.g., possible explosion in an airplane that can affect safety) and public fear (Ferreras, 2016; McGregor, 2016). This crisis received national and international attention because of the product's almost ubiquitous penetration across the world ("Worldwide Smartphone Sales," 2016). A global corporate crisis can, however, cause a falsely assumed universality of the issue if the crisis is examined only in one nation (Dogan \& Pelassy, 1984) because international crisis news has been known to have ethnocentric biases in terms of both events and geographic focus (de Vreese, Peter, \& Semetko, 2001). However, examining social media posts on a crisis in multiple nations offers a way to identify how the crisis is framed depending on national backgrounds (Swanson, 2000). To ensure a comprehensive observation and assessment, this study explores the Samsung crisis by analyzing posts on social media in three different nations: the United States, Australia, and South Korea. The three nations are chosen because they represented the highest smartphone penetration rates in the world at the time of the incident (McPhillips, 2016). South Korea and the United States manufactured the top three smartphones sold in the world: the Samsung Galaxy $\mathrm{S}_{7}$ (South Korea), the Apple iPhone 7 (United States), and the LG G5 (South Korea; Triggs, 2016). Australia was the nation where Samsung Galaxy had the largest market share, followed by South Korea (Nino, 2017). Identifying social media post frames and comparing them with user sentiment in these nations can provide clues for effective public relations (PR) strategies, corporate reputation recovery, and negative affect reduction.

\section{Crisis Framing and Cross-National Communication}

When a crisis is framed, certain aspects of the crisis are reemphasized as salient attributes. This slanted coverage affects how audiences perceive, organize, and interpret events and issues (de Vreese et al., 2001; Entman, 1993). Frames in media refer to the central idea of organizing and providing meaning to a selection of attributes by selection, presentation, and exclusion (Nelson, Clawson, \& Oxley, 1997). In other words, to frame is to select, organize, and define certain themes and aspects of reality and to emphasize events, issues, and actors of the agenda 
to make them prominent (Entman, 2004). For example, the Chinese news media framed recalled Chinese products as "unavoidable" and "exaggerated Western media," whereas the U.S. news media framed them as "worrisome" or from a "broken system" (Hong, 2013, p. 86).

In crisis communication, frames can shape the public's attribution of crisis responsibility to organizations, governments, and stakeholders. Crisis frames can influence the public's reputation perception, sentiment, behavioral intention toward the organization in crisis, and the organization's rebuild strategy (Coombs, 2007). Media play a central role in this process because the way a crisis is framed can shape the attributes of the crisis. Media select which issues to report in organizations' crisis responses, such as cause and responsibility, frames that influence audience sentiment (Coombs, 2006).

Framing can be labeled on varying levels and applications in the international context. The levels in framing are generic frames, issuespecific frames, and cross-national frames (de Vreese, 2005). Generic frames represent a broad range of aspects of a topic in different cultural contexts (de Vreese et al., 2001; Guo, Holton, \& Jeong, 2012) and provide a common analytical framework in terms of strategic aspects of the agenda (Cappella \& Jamieson, 1997). Issue-specific frames, on the other hand, pertain to detailed categories of an event (de Vreese, 2005) and present different issues from event to event. Issue-specific frames, hence, anatomize an event and enable the audience to understand the event in fine detail. Cross-national frames concern identities embedded in international issue coverage. In the cross-national comparative framing model, Guo et al. (2012) stated that media coverage is affected by culture, national identity, and/or politically driven frames. Different nations may use distinct frames to cover identical issues.

\section{Generic Frames}

Generic frames are used in analyses about crises to explain commonly categorized frames occurring in an agenda (An \& Gower, 2009). In this view, generic frames are defined as frames that are universally applicable to an agenda. Neuman, Just, and Crigler (1992) categorized types of frames dominant in the U.S. news media into four categories: conflict, economic consequences, human impact, and morality. 
Semetko and Valkenburg (200o) added attribution of responsibility to these four frames in accounting for crises. These five news frames are a generalization of crises, which can be applied to different nations (de Vreese et al., 2001).

Conflict frames in the media emphasize disagreement among individuals, groups, or organizations in the crisis as a means of capturing audience interest. An and Gower (2009) found that over $64 \%$ of analyzed news contained conflict frames. For example, U.S. newspapers framed the Fukushima nuclear power plant crisis as a conflict that could induce audience cynicism (Lazic \& Kaigo, 2013). Economic consequence frames report a crisis event in terms of the impact the crisis will have economically on individuals, groups, organizations, and nations (An \& Gower, 2009; Neuman et al., 1992). Economic frames are considered important because the consequences of the frames can affect the market and the nation.

Human interest frames emphasize psychological and emotional angles in a crisis (Semetko \& Valkenburg, 2000). Media are likely to cover feelings of outrage, empathy, sympathy, or compassion to capture and retain audience interest. Nabi (2002) discovered that different versions of news stories on domestic terrorism-each of which was designed to elicit anger and fear-induced different emotions from study participants. H. J. Kim and Cameron (2011) experimented with consumer responses to a cell phone battery explosion accident. In their study, sadness-inducing news predicted a positive attitude toward the corporation.

Morality frames look at a crisis in the context of religious or moral prescriptions (Neuman et al., 1992). Media coverage includes moral judgments such that a crisis is portrayed as preventable or unavoidable indirectly through quotations or inference. The morality frame concerns news coverage of any ethical action the entity takes to resolve the crisis.

Responsibility attribution frames suggest that news attributes responsibility for a crisis to either individual (episodic) or society (thematic; Iyengar, 1991). According to attribution theory (B. Weiner, 1993), people attribute causes of issues to behaviors. Responsibility attribution depends on the nature of a problem. Individual responsibility pertains to an emphasis on the cause of a problem (e.g., personal), whereas social 
responsibility focuses on the people who have the power to control the problem (e.g., a government, a corporation; Kang, 2013).

\section{Issue-Specific Frames}

Issue-specific frames investigate events in customized specificity because each event consists of a different list of issues. Anchoring ideas frame an event and become socially represented. In this process, some issues are neglected, and some are emphasized (Flick, 1998). Issue-specific frames can be explained as anchoring. Anchoring is the process of reducing and transforming unfamiliar ideas into categories and images (Schmitz, Filippone, \& Edelman, 2003). Through the anchoring process, certain issues are woven into the acceptable knowledge of audiences. Therefore knowing issues in one's own views can determine the way in which the audience perceives and understands issues.

Crisis topics such as U.S. national budget deficits (Jasperson, Shah, Watts, Faber, \& Fan, 1998), international airline accidents (Entman, 1991), or the Gulf War (Reese \& Buckalew, 1995) contain unique issues. In their study on the news media coverage of Alitalia's crisis, Valentini and Romenti (2011) found that the domestic press's top four issues were the financial situation, investor relations, government management, and employee relations. The international press's top four issues were investor relations, the financial situation, government management, and labor union relations (Valentini \& Romenti, 2011). Hong (2013) discovered that the news media covered issues of product quality, customer concern, and a systemic breakdown in the corporate crisis of recalled Chinese products. When a crisis is involved with a product or a service of a corporation, news issues cover a variety of issues, including the recall, side effects, scientific research evidence, complaints, lawsuits, the investigation, prevention, the crisis cause, and potential crisis solutions (D. Weiner, 2006).

\section{Cross-National Frames}

Characteristics of media organizations can affect media frames (Shoemaker \& Reese, 1996). Some media organizations are conservative or liberal (Cooper, 2002; Entman, 2010; Snow \& Benford, 1992). The political ideology of media organizations can affect framing (Scheufele, 
1999). In the process of framing, media organizations interpret social issues differently depending on their political motivations or economic needs (Simon \& Xenos, 2000).

At the macrolevel, the frames of ethnocentrism, nationalism, and professionalism influence the objectivity of coverage (Gans, 1979; Garyantes \& Murphy, 2010). The national frame refers mainly to the domestication and localization of news stories for national interest (Nossek, 2004). For example, economic issues are more heavily influenced by national interests because monetary profits are directly involved (Graber, 1993; Neuman et al., 1992). Cultural differences, ideologies, nationalism, norms, values, routines, physical distance, and business interest can influence media coverage (Garyantes \& Murphy, 2010; Shoemaker \& Reese 1996). Media organizations may apply the national frame to economic or corporate crises (Shoemaker \& Reese, 1996). The national frame and national interest frame served as a driving force of crisis coverage in Asia and Europe (Mao, 2014), which became a reconstructing factor of reality in general.

Meanwhile, the professional frame accounts for a fact-based news report rather than news framed with a slant (Nossek, 2004). When journalists (both professionals and citizens) report international crisis news, they tend to frame it as either "ours" or "theirs." After that, the professional frame (theirs) becomes subordinate to the national frame (our crisis; Nossek, 2004).

Studies have found evidence of cultural filtering in foreign event coverage, indicating that media organizations apply the "our" (national) frame rather than the "their" (professional) frame to the news for the benefit of their nations (Stevenson \& Cole, 1984; Wu, 2000). For instance, with the national frame, the U.S. media attributed responsibility for the 2013 Asiana Airlines crash to the pilots and problematic management of the flight. South Korean and Chinese media were less negative toward the corporation than were U.S. news media (Yan \& Kim, 2015). In another airplane crisis, Entman (1991) found vastly different media frames based on national interest in covering international airline tragedies. The U.S. downing of an Iranian plane was framed as a technical accident, while the Soviet downing of a South Korean airline plane was depicted as a moral outrage. 


\section{Sentiment Research on Social Media}

A crisis issue is shared or tweeted on social media through information interactions. Such user-driven news creation/sharing activities constitute (a) social media agenda setting at the first level (i.e., the news media set an agenda on social media) and at the second level (i.e., attributes of the issue become salient or insignificant on social media), (b) user comments and decisions on the issue (Schultz, Utz, \& Göritz, 2011). In this process of information interaction, users gain the power to collaboratively build crisis frames on social media (van der Meer \& Verhoeven, 2013), and the media tone set on social media news posts about crisis issues might affect the public's sentiment toward the issues (J. Kim et al., 2016).

Sentiment analysis has been used widely in social media research because it can measure feelings toward communication in an interface. Sentiment on social media is defined as the attitudinal valence of users' mentions (Homburg, Ehm, \& Artz, 2015). In other words, social media posts about a crisis in terms of sentiment can be viewed as negative, positive, or neutral (Choi \& Lin, 2009). Users express negative emotions with anger or fear. The neutral response can be fact sharing. Positive emotions can include relief and sympathy. In dealing with crisis issues, people tend to seek more social cues to check the climate of majority opinions on issues because they want to be harmonious with the socially desirable and normative expectations of others (J. Kim et al., 2016). Past research shows that people are likely to pay attention to crisis communication via social media more than they do via traditional media because social media provide not only real-time information but also social cues, such as user comments (Brummette \& Fussell, 2015; Utz, Schultz, \& Glocka, 2013). Hence the sentiment analysis of crisis communication on social media could provide a social cue for gauging public attitudes on the issue (J. Kim et al., 2016).

Drawn from the review of framing in corporate crises and social media, this study posits that social media posts about the Samsung Galaxy Note 7 explosion consist of crisis frames and sentiment. Research questions reflecting the inquiries are as follows: 
RQ1: How are generic frames (RQ1A), issue-specific frames (RQ1B), and cross-national frames (RQ1C) about the Samsung crisis used in social media posts?

RQ2: How is sentiment about the Samsung crisis posts used on social media?

RQ3: How do generic frames (RQ3A), issue-specific frames (RQ3B), and cross-national frames (RQ3C) for the Samsung crisis relate to sentiment?

\section{Method}

\section{Sampling Procedure}

This study used the search keyword "Samsung Galaxy Note 7" for the United States, Australia, and South Korea on Twitter. From the three nations, the search between August 1, 2016, and January 31, 2017, yielded 549,424 tweets from the United States, 24,628 tweets from Australia, and 5,036 tweets from South Korea, totaling 579,088 tweets. We used Synthesio as the data collection platform.

The coding period was set for two reasons. First, the Galaxy Note 7 model was released to the public on August 2, 2016. The first explosion was reported on August 19, 2016, in South Korea. Second, after a series of explosions, recalls, bans on carrying the Galaxy Note 7 on flights, and suspended production of the phone, Samsung officially announced the cause of the explosion on January 22, 2017. This study analyzed the tweets during the entire timeline of the explosion.

Twitter is used as a social media platform in analysis for several reasons. Twitter provides a ready source of data for researchers interested in public opinion. Twitter, with its 140 -character posts, ${ }^{1}$ consists of news, tables, statistics, and charts (Driscoll \& Walker, 2014). For both professional and citizen journalists, Twitter is a supportive resource for reporting, delivering, and sharing information. Twitter is used as an information source for crises more than other social media platforms because it is fast and up to date. On Twitter, users post "trending topics" with hashtags and links. For this reason, researchers and journalists rely on Twitter for interpreting and giving context to news events (Valenzuela, Puente, \& Flores, 2017). In addition to the general merits 
of Twitter mentioned earlier, another reason for using Twitter is that it enables an equal comparison of the three nations. In this sense, Twitter is a more appropriate content source for the analysis of the three nations than other popular platforms, such as Naver (the largest web portal in South Korea), Facebook, and YouTube.

Three individuals participated in the data coding procedures and took charge of each nation (United States, Australia, and South Korea). Using a systematic data collection approach, the coders chose the first tweet of each day in each month. The selection yielded 184 tweets (30 for September and November; 31 for August, October, December, and January). Then, by selecting the three months with the most tweets, the remaining 16 posts were chosen $(N=200)$. They were six from the top 2 months $(n=12)$ and four from the third month $(n=4)$. Following the coding rules, a total of 600 tweets (200 from each nation) were drawn for analysis. While most Twitter studies use large samples, several framing studies have analyzed a sample size similar to the current study's. Framing studies on Twitter use relatively small samples out of many posts because aspects and valence are represented better by manual coding than with big data (e.g., García-Perdomo, 2017; Manor \& Crilley, 2018; Pond \& Lewis, 2019).

\section{Coding Instrument}

The unit of analysis is a Twitter post. The first coding scheme consisted of generic and issue-specific frames (An \& Gower, 2009; Flick, 1998). Five generic frames were applied to the Samsung Galaxy Note 7 explosion case: conflict, economic consequences, human impact, morality, and attribution (presence $=1$, absence $=0$; Table 1 ). Since the Samsung case is concerned with a product, framing items from previous research about news media coverage of products were used (Hong, 2013; Valentini \& Romenti, 2011). The adjusted items in the Samsung Note 7 explosion context are product quality, customer concern, corporate breakdown, recall, side effect, evidence, employee, lawsuit, business expert, investigation, prevention, government, cause, solution, safety, and design (presence $=1$, absence $=0$; Table 1 ). There were no additional frame items to create in the coding process, which met the conceptual saturation of frames. 


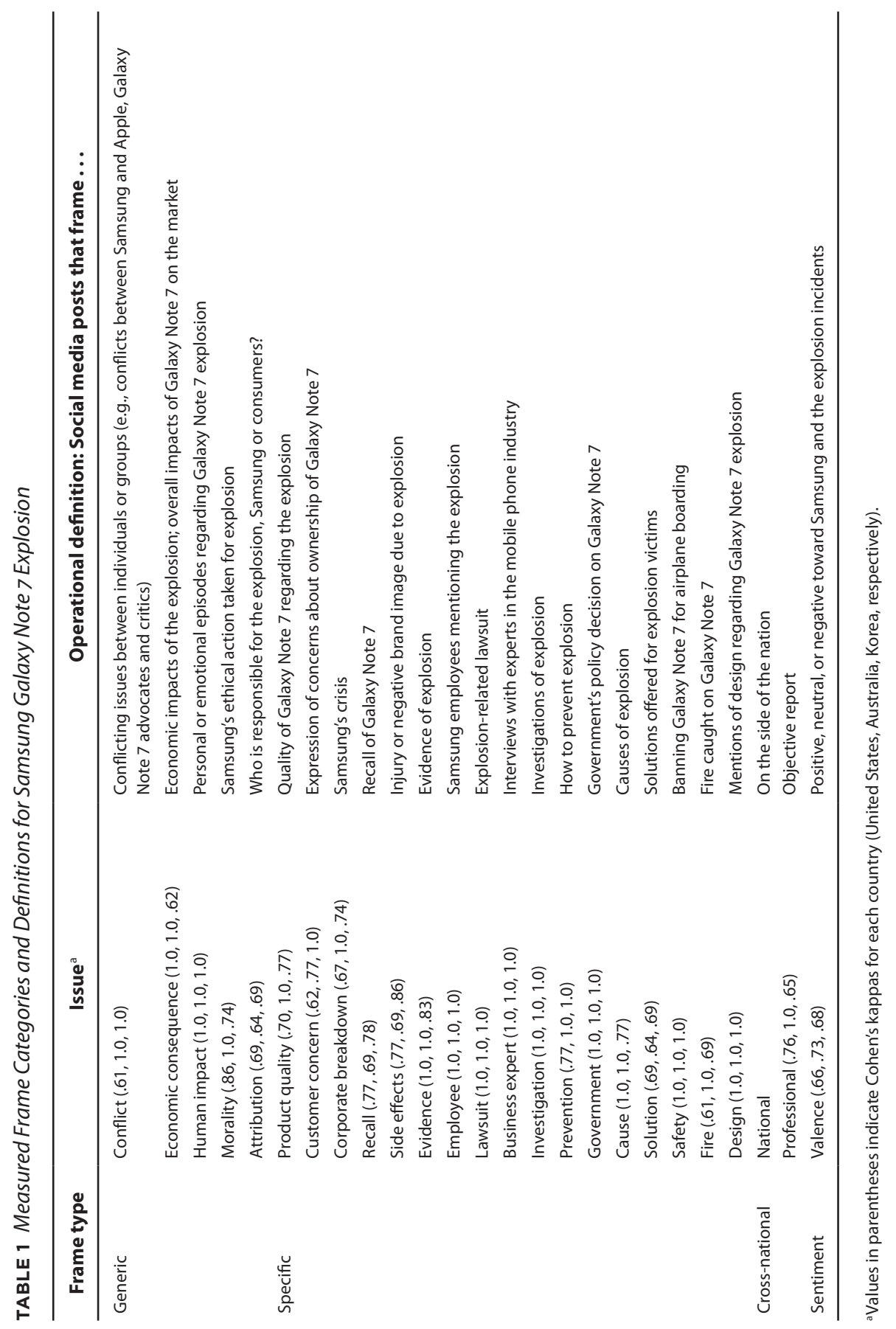


The coders also judged whether the posts contained aspects of the national frame (on the side of the nation; coded as 2), the professional frame (objective report; coded as 1), or not identified (coded as o; Nossek, 2004; Table 1). Regarding sentiment, the coding categories were positive (2), neutral (1), and negative (o). When a post contained a relieving, sympathetic, or favorable comment, it was coded as positive (e.g., "Samsung Galaxy Note 7's iris scanner might be the coolest smartphone feature ever"). Posts containing fact sharing were coded as neutral (e.g., "Here are some pics of Samsung Galaxy Note 7"). When a user expressed a negative emotion with anger or fear in the post, it was coded as negative (e.g., "Samsung Galaxy Note 7 disappoints; iPhone 7 wins before launch?"). The validity of the coding was cross-checked in intercoder reliability tests.

\section{Intercoder Reliability}

Three coders participated in intercoder reliability tests. The coder of the U.S. sample drew $10 \%$ of the Australian data. The coder of the Australian sample drew $10 \%$ of the South Korean data. The coder of the South Korean sample drew $10 \%$ of the U.S. data. All three coders conducted Cohen's kappa for intercoder agreement of categorical data. Therefore the three-nation data were cross-checked to ensure that coding reached a mutual consensus. A few variable discrepancies were present on the first attempt. After discussion, the reliability tests yielded acceptable kappas (see Table 1 for individual kappa values). Overall, the average of the three-nation reliability tests was acceptable, with a Cohen's kappa value of .83 (Landis \& Koch, 1977).

\section{Findings}

Frequency analyses and Cramer's $V$ correlations for categorical data were conducted for the posed research questions. RQ1A asked about the distribution of generic frames in posts about the Samsung crisis (Table 2). Table 2 demonstrates that tweets about the crisis most frequently included attribution $(n=131)$, followed by morality $(n=106)$, conflict $(n=61)$, and economic consequence $(n=60)$. Generic frames were posted in October $2016(n=95)$ the most, followed by September $(n=$ $85)$ and November $(n=78)$. 


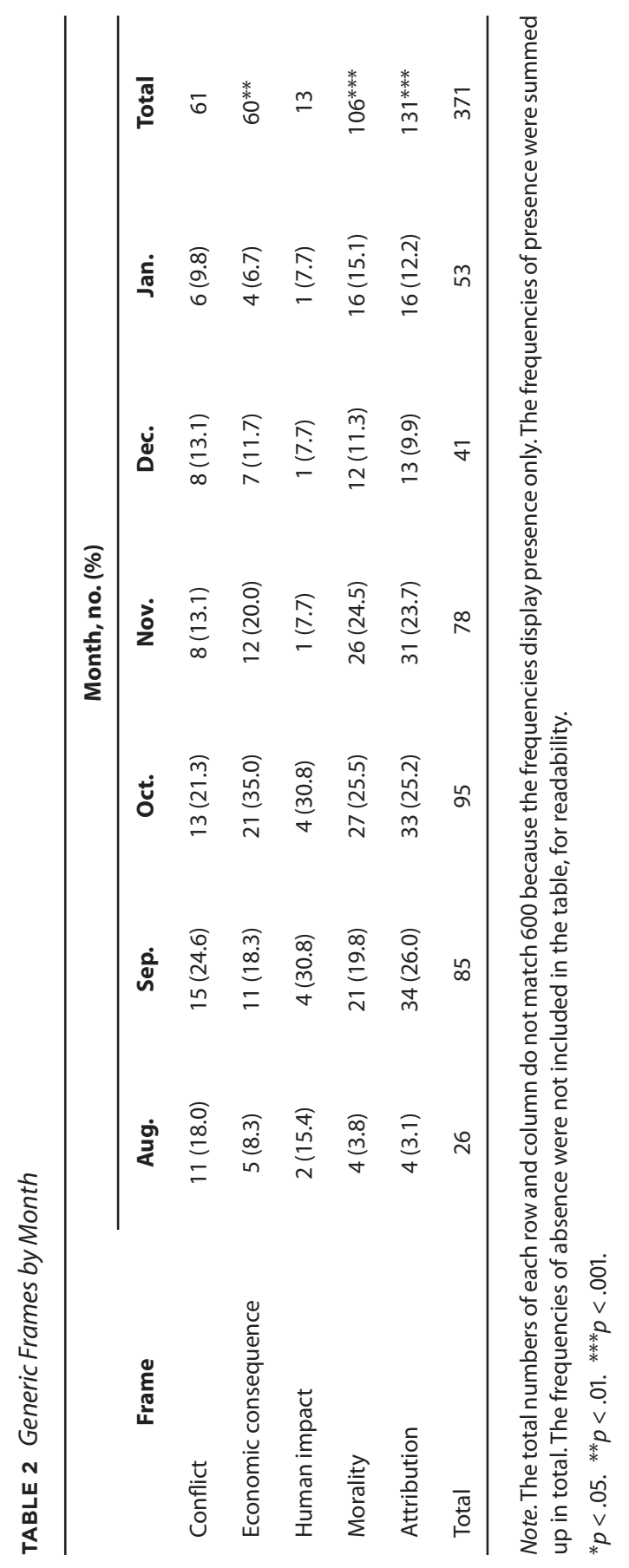




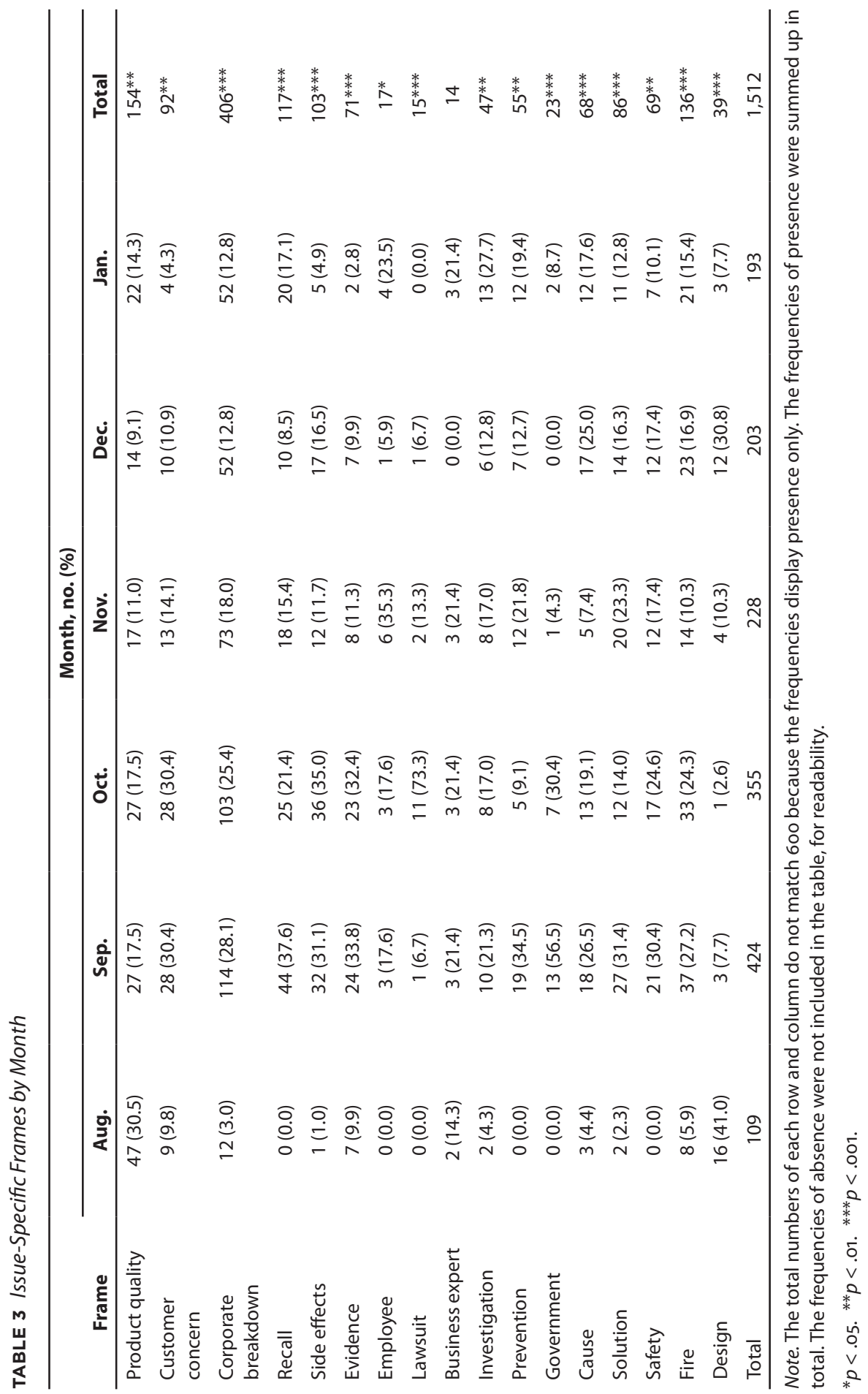




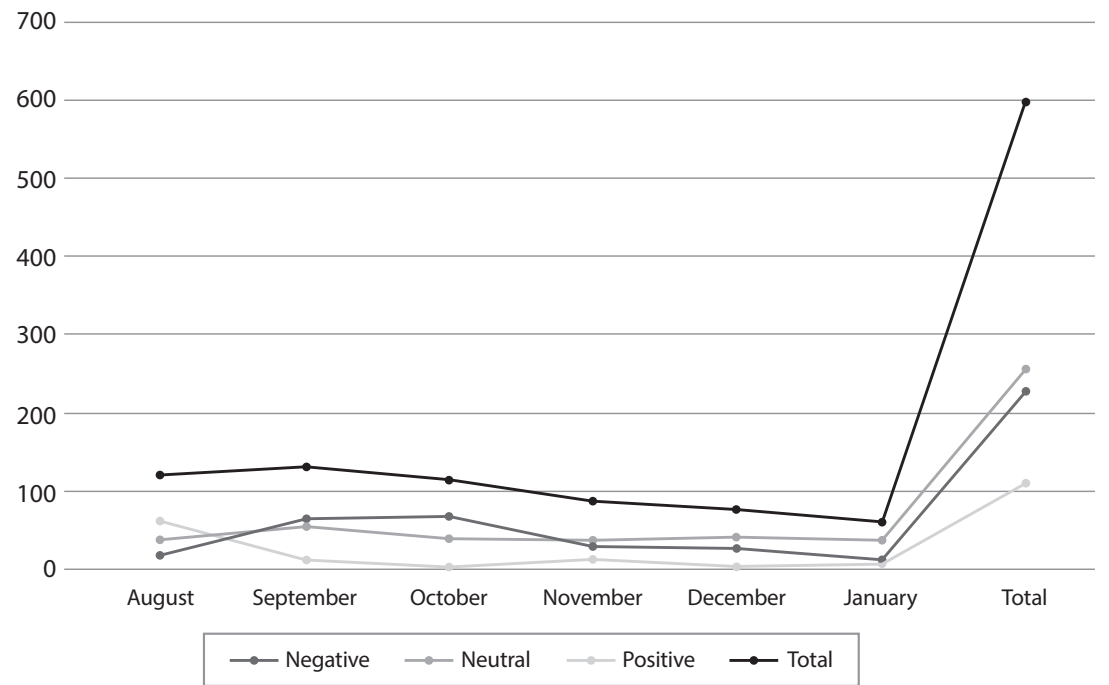

FIGURE 1 Distribution of sentiment by month. The sentiment by month is significantly different, $\chi^{2}(10, N=600)=144.18, p<.001$.

RQ1B questioned how issue-specific frames were posted on Twitter during the incident period (August 2016-January 2017; Table 3). The result showed that tweets were highly focused on corporate breakdown (Samsung's crisis due to explosions; $n=406$ ). The product quality issue was the second most tweeted topic during the incident period $(n=154)$, followed by fire $(n=136)$, recall $(n=117)$, and side effects $(n=103)$. The least tweeted issue was business expert sources $(n=14)$.

$\mathrm{RQ1C}$ asked about the distribution of cross-national frames (national or professional). Analysis revealed that there were more posts about the professional frame $(n=104)$ than the national frame $(n=4)$, though frame frequency by month was not statistically significant, $\chi^{2}(10, N=$ $600=14.91, n s$. RQ2 asked about sentiment in the posts. Analysis discovered that the least frequently observed sentiment was positive posts $(n=112$; Figure 1$)$. There were more posts with neutral sentiment $(n=$ $258)$ than negative $(n=230)$ or positive sentiment $(n=112)$.

When comparing the relationship between generic frames and sentiment, as asked in RQ3A, morality and sentiment were significantly correlated with each other, $V=.27, p<.001$, indicating that Twitter users viewed posts framing the incident in terms of morality more negatively 
TABLE 4 Cramer's V Correlations Between Generic Frames and Sentiment

\begin{tabular}{lccccc}
\hline & \multicolumn{3}{c}{ Sentiment, no. (\%) } & & \\
\cline { 2 - 4 } \multicolumn{1}{c}{ Frame } & Negative & Neutral & Positive & Total & $\boldsymbol{V}$ \\
\hline Conflict & $26(42.6)$ & $23(37.7)$ & $12(19.7)$ & 61 & 0.04 \\
$\begin{array}{l}\text { Economic } \\
\text { consequence }\end{array}$ & $26(43.3)$ & $22(36.7)$ & $12(20.0)$ & 60 & 0.04 \\
$\begin{array}{l}\text { Human } \\
\text { impact }\end{array}$ & $6(46.2)$ & $3(23.1)$ & $4(30.8)$ & 13 & 0.06 \\
Morality & $70(66.0)$ & $28(26.4)$ & $8(7.5)$ & 106 & $0.27^{* * *}$ \\
Attribution & $80(61.1)$ & $43(32.8)$ & $8(7.1)$ & 131 & $0.26^{* * *}$ \\
Total & 208 & 119 & 44 & 371 & \\
\hline
\end{tabular}

Note. $N=371$. The total numbers of each row and column do not match 600 because the frequencies display presence only. The frequencies of presence were summed up in total. The frequencies of absence were not included in the table, for readability.

${ }^{*} p<.05 .{ }^{* *} p<.01 .{ }^{* * *} p<.001$.

than positively. The same finding was also observed between attribution and sentiment, $V=.26, p<.001$ (Table 4).

RQ3в looked at the relationship between issue-specific frames and sentiment. Most issue-specific frames were correlated with negative sentiment (Table 5). Corporate breakdown was highly associated with negative sentiment, $V=.45, p<.001$. Customer concerns, side effects, fires on the phone, safety, and explosion evidence were significantly associated with negative sentiment. However, the significant association between product quality and sentiment demonstrated that several supporters of Samsung posted the quality of Galaxy Note 7 more positively than neutrally, $V=.21, p<.001$. Regarding design, there was more positive sentiment than negative, $V=.19, p<.001$. RQ3C questioned how cross-national frames were related to sentiment. As shown in Table 6, there was no significant relationship between them. No discrepancies were found between negative and positive sentiment by cross-national frames. 


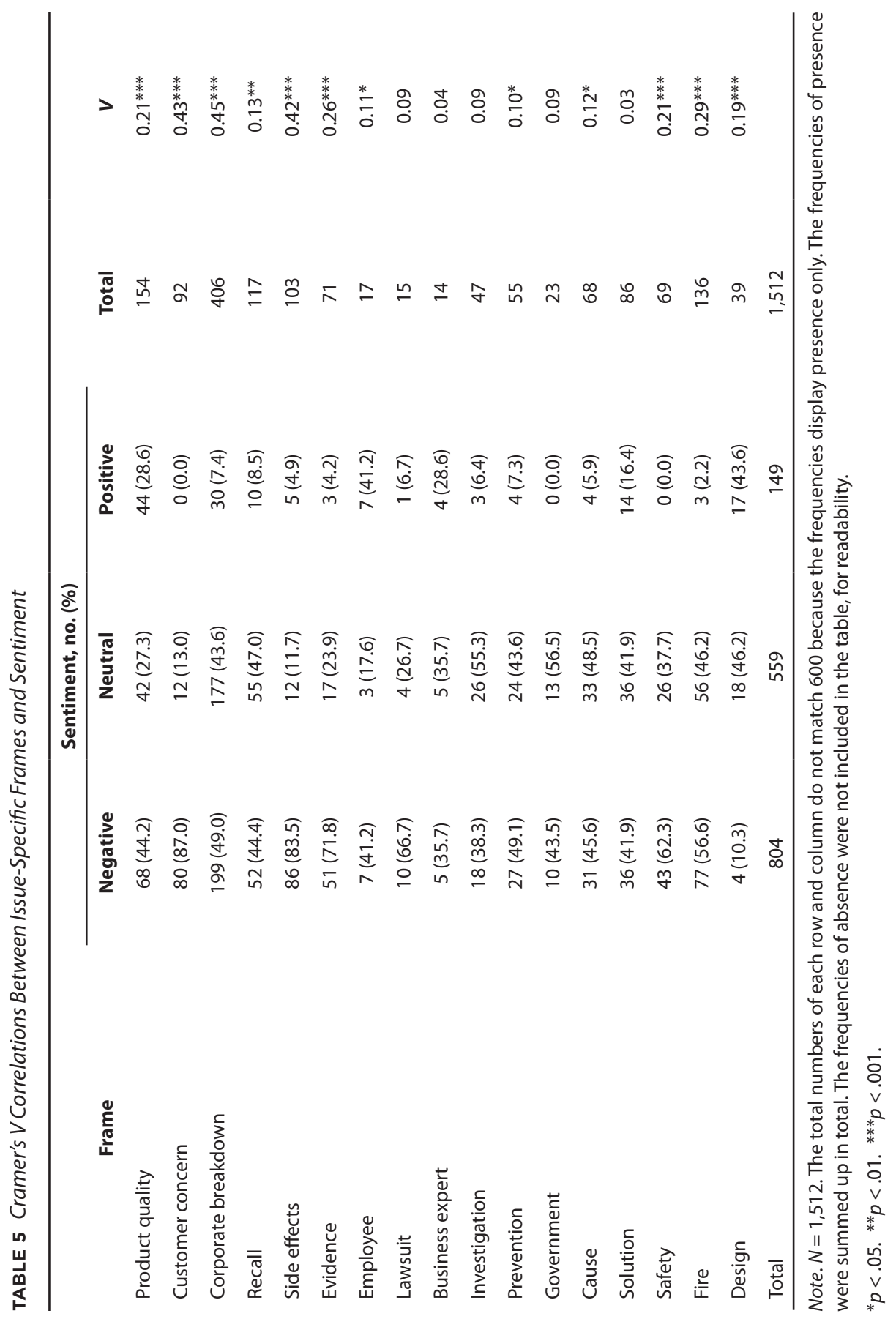


TABLE 6 Cramer's V Correlations Between Cross-National Frames and Sentiment

\begin{tabular}{|c|c|c|c|c|c|}
\hline \multirow[b]{2}{*}{ Frame } & \multicolumn{3}{|c|}{ Sentiment } & \multirow[b]{2}{*}{ Total } & \multirow[b]{2}{*}{$V(N)$} \\
\hline & Negative & Neutral & Positive & & \\
\hline Not identified & 195 (39.6) & $210(42.7)$ & $87(17.7)$ & 492 & \\
\hline Professional & $33(31.7)$ & $46(44.2)$ & $25(24.0)$ & 104 & \\
\hline National & $2(50.0)$ & $2(50.0)$ & $0(0.0)$ & 4 & \\
\hline Total & 230 & 258 & 112 & 600 & $0.06(600)^{\mathrm{a}}$ \\
\hline
\end{tabular}

Note. Values in parentheses indicate percentages for each cross-national frame.

aThe total number matches 600 because the frame items include all responses (professional, national, and not identified).

\section{Discussion}

This analysis of Samsung crisis posts demonstrates that social media are a sphere of disseminating news, opinions, and sentiment. Posts on social media may affect both the corporation and the public in terms of reputation management, PR strategies, and behavioral intentions. This study investigated framing types and expressed sentiment in Twitter posts about the Samsung crisis and associated sentiment with particular framing types. These research questions are of importance for both academics and practitioners for several reasons. Nowadays, global organizations are crisis prone due to the snowballing and unlimited nature of global media platforms such as Twitter. Also, as digital media have evolved, so has the audience. As opposed to customers at brick-and-mortar stores-the vast majority of which are valued customers-users of social media tend to respond quickly and often without mercy when a corporation faces a crisis, thereby exacerbating the issue via sharing behaviors. This study paid special attention to Twitter as one of the most influential social media platforms, especially when conveying breaking stories to the masses (Murthy, 2011).

The findings of this study demonstrate where sentiment lies during or after a crisis. The first set of research questions (RQ1) concerned how an international corporate crisis was framed on social media. In RQ1A on generic frames, findings demonstrated that attribution and morality frames were more frequently posted than conflict, economic consequence, and human impact frames. For instance, a South Korean 
user mentioned Samsung's responsibility for the explosion on Twitter, writing, "OMG, should Samsung pay for the damage to the vehicle due to the phone explosion?" However, there were relatively few ethical actions or responsibility posts from Samsung. The most frequently used frame (attribution) this study found is congruent with previous research on news framing in traditional media (Semetko \& Valkenburg, 2000), indicating a consistency of framing regardless of the news dissemination platform.

As the findings of RQ1B illustrate, posts expressing negative sentiment (e.g., corporate breakdown, product quality, fire, and recall) were more frequently tweeted than posts expressing positive sentiment (e.g., solution, prevention, and safety). The pattern of issue coverage between legacy news media (Hong, 2013) and Twitter was similar in issue-specific framing. Findings suggest that Twitter users perform secondary crisis communication (SCC), which is defined as conveying news and others' posts about the crisis (Zheng, Liu, \& Davison, 2018). Social media users' cognitive reputation in Samsung resulted in SCC, as they felt morally violated through the explosion incident. During and after the crisis, many posts highlighted the corporate breakdown of Samsung. For instance, a U.S. user's retweet reads, "There's a worldwide recall on the new Samsung Note 7's. It's been reported they're catching fire. Return it ASAP.”

The analysis for RQ1C found that there were more professional frames than national frames (see the appendix for sample tweets of cross-national frames). This result shows a slightly different pattern than the past research on crisis news coverage, which was national frame oriented (Mao, 2014; Shoemaker \& Reese, 1996). We found more cosmopolitanism (no significant difference among the nations) than in the national frame. It should be noted that traditionally and conventionally framing theory itself has been utilized to identify and analyze "how journalists depict a crisis." Yet this study applies framing theory differently than the previous approach, as we look at how global online users respond to a crisis rather than investigate press coverage. To be specific, in previous research (Mao, 2014), the Chinese press constructed two crises (the Asian financial crisis and the European debt crisis) with many levels of the national frame. The difference in findings between the current and previous studies might be due to the different natures of newspapers and Twitter. 
While we found the value of framing as theoretical and methodological tool for examining online audiences' collective selection of information and sharing behaviors, we also found that cosmopolitanism on the global media might prevail over the national frame. Twitter is a global medium, unlike traditional media platforms, such as local newspapers or national broadcasting, so the national frame might have disappeared or been watered down in comparison to a traditional form of media coverage. In an online sphere, global audiences and issue-based communities are formed and activated. Therefore the result might have been different than previous findings due to the different nature and scope of digital media platforms compared to traditional ones.

The second aim of the current study was to explore the distribution of sentiment in Twitter posts on the Samsung crisis (RQ2). Given the finding of more negative sentiment than positive sentiment, Twitter users may hold the power to collaborate in crisis frame building (van der Meer \& Verhoeven, 2013). Twitter users' power is an interactive process in which some posts on a topic can capture other users' attention. Once the posts capture attention, they are retweeted. For example, a U.S. user retweeted the hyperlinked news with negative sentiment: "Samsung Galaxy Note 7 Disappoints; iPhone 7 Wins Before Launch? http://dlvr.it/M7mm9x \#newiphone."

A significant relationship was found between social media post frames and audience sentiment (RQ3). When correlations between generic frames and sentiment were tested in Cramer's $V$ analyses, attribution and morality were correlated with negative sentiment. Therefore this study suggests that prompt and constant responses to a crisis posted on the corporation's social media pages can be used for shares and retweets. In this way, morality and attribution frames may be framed positively.

This interpretation of generic frames and sentiment applies to the comparison between issue-specific frames and sentiment. Corporate breakdown, customer concerns, and side effects were the top three issues highly associated with negative sentiment. This comparison suggests that companies should manage social media posts to respond to a crisis strategically. Active posts, such as apologies, ideas to overcome corporate breakdowns, management of side effects, and the provision of solutions, can be some response options. 
Overall, most of the negative posts are centered around the "issuespecific frame" with regard to product failure, not the national frame of the issue. Given these results, crisis communicators should note that the rebuild strategy is a recommendable action to turn around negative sentiment with crisis relief (Coombs, 2007). Also, this study's results shed light on the importance and role of Twitter in cross-national crisis situations, as negative sentiment mushroomed with information sharing among global user communities. Samsung and influencers supporting the corporation would have used Twitter to rebuild Samsung's reputation proactively. However, not enough suitable and effective responses and/or thoughtful communication messages from Samsung were found in response to product failure and corporate breakdown. Thus Samsung seemed to fail to win immediate attention from customers in terms of handling the issue. This might be the case for other global IT corporations. IT corporations might not have feasible communication solutions or communication strategies against any potential and/or impending crises.

Audiences used Twitter for the news and information dissemination of the explosion in the form of retweets and comments. The current study found that users externalized breaking news on the explosion by hyperlinking. Hyperlinking invoked public discussion on the incident. Users participated in retweeting and commenting behaviors with personal sentiment. Past research demonstrated that social media users interpret news frames and create their own discussion forums on Twitter (Valenzuela, Piña, \& Ramírez, 2017; Wasike, 2013). Therefore Twitter users create a new sphere of discussion by sharing frames (generic, issue specific) with other users actively.

\section{Theoretical and Practical Implications}

This study analyzed social media posts about a corporate crisis regarding generic, issue-specific, cross-national frames and regarding sentiment. This approach opens the possibility of combining framing and other crisis communication theories. The framing perspective can be incorporated into situational crisis communication theory in the social media context. The issues posted on social media can be elaborated on generic and issue-specific frames. Different crisis types (victim, accidental, and intentional) can be observed in those issues 
on social media. Eventually, some posts can predict audiences' positive or negative attitudes toward the corporation (Kim \& Cameron, 2011).

The dominant negative posts on social media suggest that the platform can be an influential channel for the global audience. In response to the crisis, findings reveal that social media users are highly concerned about corporate morality and attribution. Therefore corporations can pay attention to ethical and responsibility aspects in their social media posts. Given the positive relationship between issue-specific frames and negative sentiment, corporations may continually monitor social media posts and post emotional stories in an effort to elicit positive audience perceptions (Spence, Sellnow-Richmond, Sellnow, \& Lachlan, 2016).

\section{Limitations and Suggestions for Future Research}

This study contains several methodological limitations. The sample $(N=$ 600 ) out of more than 100,000 Twitter posts does not fully reflect the Samsung Note 7 explosion. Although framing research uses a relatively small sample for manual coding, sample representativeness is a study limitation. Future research on big data can represent a valid state of the explosion incident. Intermedia agenda setting research can warrant the flow of social media posts on this topic. An expanded analysis of social media and traditional news media can show the power of media channels covering the issue and public perceptions. Therefore surveying the public about attitudes toward a corporation can provide further answers. The survey questions for the public could be drawn from a content analysis of social media posts. Then the public could indicate how often they view the messages and evaluate the experience. Future research can compare social media posts with public attitudes.

In conclusion, the results of the present study imply that Twitter was used more for negative posts than for positive ones on the Samsung Galaxy Note 7 explosion case. Users paid attention to corporate morality, attribution, corporate breakdown, product quality, and the recall. Even though the national frame was not a significant frame, negative sentiment was prominent. The findings suggest that analyses of Twitter can provide a content structure of the Samsung Galaxy Note 7 explosion. 


\section{Appendix: Sample Tweets of Cross-National Frames}

Professional frame: RT @verge: Breaking: Samsung will reportedly issue worldwide recall of Galaxy Note 7 http://www.theverge .com/2016/9/1/12759912/samsung-galaxy-note-7-recall?utm_campaign =theverge\&utm_content $=$ chorus\&utm_medium $=$ social\&utm_source $=$ twitter

National frame: RT @themoneygame: Korea’s won tumbles as BOK warns of possible Samsung Galaxy Note 7 fallout https://t.co/aEv7p C6amc

Not identified: RT @techtimestv: Here are some pics of Samsung Galaxy Note $7 @$ @echtimestv 


\section{Acknowledgement}

The authors would like to express gratitude to Synthesio for its provision of the Twitter data used for analysis in this study.

Seok Kang, $\mathrm{PhD}$, is professor in digital media studies with an emphasis on mobile media effects, digital journalism, social media, and digital media production. He is currently interested in the impacts of virtual reality and augmented reality on users' processing of mediated messages, engagement, and behavioral intention. The topics of his recent publications include virtual reality news and credibility, adoption of sports apps, sustainable development of urban community, and social media's influence on suicidal ideation.

KyuJin Shim, $\mathrm{PhD}$, is lecturer in media and communications at the University of Melbourne. Prior to joining the University of Melbourne in 2018, KyuJin was assistant professor of corporate communication at Singapore Management University, Singapore. KyuJin's research interests are corporate ethics and social responsibility, social media, crisis management, and international PR with regard to globalization and digitization in communication.

Jiyoun Kim, $\mathrm{PhD}$, a communication science researcher with a special emphasis on contested issues, has been concerned with the dynamics of public engagement in emerging interactive media. Currently she is interested in how social media influences public attitudes, interest, and engagement toward controversial issues. Particularly, her recent research focuses on how online social cues stimulated individuals' cognitive processing and issue engagement intention (e.g., information dissemination and endorsement).

\section{ORCID}

Seok Kang (D) https://orcid.org/oooo-0oo1-9713-3253 


\section{Note}

1. Twitter started a 280-character tweet limit on November 7, 2017.

\section{References}

An, S., \& Gower, K. K. (2009). How do the news media frame crises? A content analysis of crisis news coverage. Public Relations Review, 35, 107-112. https://doi.org/10.1016/j.pubrev.2009.01.010

Brummette, J., \& Fussell, S. H. (2015). Using Twitter as a means of coping with emotions and uncontrollable crises. Public Relations Review, 41, 89-96. https://doi.org/10.1016/j.pubrev.2014.10.009

Cappella, J. N., \& Jamieson, K. H. (1997). Spiral of cynicism: The press and the public good. New York, NY: Oxford University Press.

Ceron, A. (2015). Internet, news, and political trust: The difference between social media and online media outlets. Journal of Computer-Mediated Communication, 20, 487-503. https://doi.org/10.1111/jcc4.12129

Choi, Y., \& Lin, Y. H. (2009). Consumer responses to Mattel product recalls posted on online bulletin boards: Exploring two types of emotion. Journal of Public Relations Research, 21, 198-207. https://doi.org/10.1080 /10627260802557506

Coombs, W. T. (2006). The protective powers of crisis response strategies. Journal of Promotion Management, 12, 241-26o. https://doi.org/10.1300 /Jo57V12no3_13

Coombs, W. T. (2007). Protecting organization reputation during a crisis: The development and application of situational crisis communication theory. Corporate Reputation Review, 10, 163-176. https://doi.org/10.1057 /palgrave.crr.1550049

Coombs, W. T., \& Holladay, S. J. (2004). Reasoned action in crisis communication: An attribution theory-based approach to crisis management. In D. P. Millar \& R. L. Heath (Eds.), Responding to crisis: A rhetorical approach to crisis communication (pp. 95-115). Hillsdale, NJ: Erlbaum.

Cooper, A. H. (2002). Media framing and social movement mobilization: German peace protest against INF missiles, the Gulf War and NATO peace enforcement in Bosnia. European Journal of Political Research, 41, 37-80. https://doi.org/10.1111/1475-6765.00003 
de Vreese, C. H. (2005). News framing: Theory and typology. Information Design Journal + Document Design, 13, 51-62. https://doi.org/10.1075/idjdd .13.1.06vre

de Vreese, C. H., Peter, J., \& Semetko, H. A. (2001). Framing politics at the launch of the euro: A cross-national comparative study of frames in the news. Political Communication, 18, 107-122. https://doi.org/10.1080 /105846001750322934

Diehl, T., Weeks, B. E., \& Gil de Zúñiga, H. (2016). Political persuasion on social media: Tracing direct and indirect effects of news use and social interaction. New Media \& Society, 18, 1875-1895. https://doi.org/10.1177 /2F1461444815616224

Dogan, M., \& Pelassy, D. (1984). How to compare nations: Strategies in comparative politics. Chatham, NJ: Chatham House.

Driscoll, K., \& Walker, S. (2014). Working within a black box: Transparency in the collection and production of big Twitter data. International Journal of Communication, 8, 1745-1764. Retrieved from https://ijoc.org/index.php /ijoc/article/view/2171

Entman, R. M. (1991). Framing US coverage of international news: Contrasts in narratives of the KAL and Iran air incidents. Journal of Communication, 41, 6-27. https://doi.org/10.1111/j.1460-2466.1991.tbo2328.x

Entman, R. M. (1993). Framing: Toward clarification of a fractured paradigm. Journal of Communication, 43, 51-58. https://doi.org/10.1111/j.1460-2466.1993 .tbo1304.X

Entman, R. M. (2004). Projections of power: Framing news, public opinion, and U.S. foreign policy. Chicago, IL: University of Chicago Press.

Entman, R. M. (2010). Media framing biases and political power: Explaining slant in news of campaign 2008. Journalism, 11, 389-408. https://doi .org/10.1177/2F1464884910367587

Facebook. (2011). Most shared articles on Facebook in 2011. Retrieved from https://www.facebook.com/notes/facebook-media/most-shared-articles -on-facebook-in-2011/283221585046671/

Ferreras, J. (2016, September 10). Samsung Galaxy Note 7 explosions trigger flight warnings in Canada. Huffington Post Canada. Retrieved from https:// www.huffingtonpost.ca/2016/o9/10/samsung-galaxy-note-7-explosion -planes_n_1194366o.html

Flick, U. (1998). Everyday knowledge in social psychology. In U. Flick (Ed.), 
The psychology of the social (pp. 1-14). Cambridge, England: Cambridge University Press.

Gans, H. J. (1979). Deciding what's news. New York, NY: Pantheon.

García-Perdomo, V. (2017). Between peace and hate: Framing the 2014 Colombian presidential election on Twitter. Cuadernos.Info, 41, 57-70. https://doi.org/10.7764/cdi.41.1241

Garyantes, D., \& Murphy, P. (2010). Success or chaos?: Framing and ideology in news coverage of the Iraqi. International Communication Gazette, 72, 151-170. https://doi.org/10.1177/2F1748048509353866

Graber, D. A. (1993). Media power in politics (3rd ed.). Washington, DC: CQ Press.

Guo, L., Holton, A., \& Jeong, S. H. (2012). Transnational comparative framing: A model for an emerging framing approach. International Journal of Communication, 6, 1918-1941. Retrieved from https://ijoc.org/index.php /ijoc/article/view/1414/771

Hajdu, M., Pápay, B., Szántó, Z., \& Tóth, I. J. (2018). Content analysis of corruption coverage: Cross-national differences and commonalities. European Journal of Communication, 33, 7-21. https://doi.org/10.1177/2Fo267323117750673

Hindman, M. (2009). The myth of digital democracy. Princeton, NJ: Princeton University Press.

Homburg, C., Ehm, L., \& Artz, M. (2015). Measuring and managing consumer sentiment in an online community environment. Journal of Marketing Research, 52, 629-641. https://doi.org/10.1509/jmr.11.0448

Hong, S. C. (2013). Scare sells? A framing analysis of news coverage of recalled Chinese products. Asian Journal of Communication, 23, 88-106. https:// doi.org/10.1080/01292986.2012.717090

Iyengar, S. (1991). Is anyone responsible? How television frames political issues. Chicago, IL: University of Chicago Press.

Jasperson, A. E., Shah, D. V., Watts, M., Faber, R. J., \& Fan, D. P. (1998). Framing the public agenda: Media effects on the importance of the federal budget deficit. Political Communication, 15, 205-224. https://doi.org /10.1080/10584609809342366

Kang, S. (2013). Network news coverage of autism: An analysis of news framing. Disability \& Society, 28, 245-259. https://doi.org/10.1080/09687599 .2012 .705056

Khuntia, J., Sun, H., \& Yim, D. (2016). Sharing news through social networks. 
International Journal on Media Management, 18, 59-74. https://doi.org/10 $.1080 / 14241277.2016 .1185429$

Kim, H. J., \& Cameron, G. T. (2011). Emotions matter in crisis: The role of anger and sadness in the public's response to crisis news framing and corporate crisis response. Communication Research, 38, 826-855. https:// doi.org/10.1177/2Foo93650210385813

Kim, J., Brossard, D., Scheufele, D. A., \& Xenos, M. (2016). “Shared” information in the age of big data: Exploring sentiment expression related to nuclear energy on Twitter. Journalism and Mass Communication Quarterly, 93, 430-445. https://doi.org/10.1177/2F1077699016640715

Landis, J. R., \& Koch, G. G. (1977). The measurement of observer agreement for categorical data. Biometrics, 33, 159-174. https://www.jstor.org /stable/2529310

Lazic, D., \& Kaigo, M. (2013). US press coverage of the Fukushima nuclear power plant accident: Frames, sources and news domestication. Media Asia, 40, 260-273. https://doi.org/10.1080/01296612.2013.11689975

Manor, I., \& Crilley, R. (2018). Visually framing the Gaza War of 2014: The Israel ministry of foreign affairs on Twitter. Media, War \& Conflict, 11, 369-391. https://doi.org/10.1177/1750635218780564

Mao, Z. (2014). Cosmopolitanism and global risk: News framing of the Asian financial crisis and the European debt crisis. International Journal of Communication, 8, 1029-1048. Retrieved from https://ijoc.org/index.php/ijoc /article/view/2240/1115

McGregor, J. (2016, September 28). Samsung's Galaxy Note 7 is finished. Forbes. Retrieved from https://www.forbes.com/sites/jaymcgregor/2016/o9/28 /samsungs-exploding-battery-problem-will-finish-the-note-7/\#a67d99 $71 \mathrm{f}$ ad

McPhillips, D. (2016, March 21). The 10 countries with the highest smartphone penetration. U.S. News. Retrieved from https://www.usnews.com/news /best-countries/articles/2016-03-21/the-10-countries-with-the-highest -smartphone-penetration

Murthy, D. (2011). Twitter: Microphone for the masses? Media, Culture \& Society, 33, 779-789. https://doi.org/10.1177/0163443711404744

Nabi, R. L. (2002). Anger, fear, uncertainty, and attitudes: A test of the cognitive-functional model. Communication Monographs, 69, 204-216. https:// doi.org/10.1080/03637750216541 
Nelson, T., Clawson, R. A., \& Oxley, Z. M. (1997). Media framing of a civil liberties conflict and effect on tolerance. American Political Science Association, 91, 567-583. https://doi.org/10.2307/2952075

Neuman, W. R., Just, M. R., \& Crigler, A. N. (1992). Common knowledge. Chicago, IL: University of Chicago Press.

Nino, A. (2017, January). 25 countries where Samsung Galaxy smartphones have the largest market share. Insider Monkey. Retrieved from https://www.insider monkey.com/blog/25-countries-where-samsungs-galaxy-smartphones -have-the-largest-market-share-522911/? singlepage $=1$

Nossek, H. (2004). Our news and their news: The role of national identity in the coverage of foreign news. Journalism, 5, 343-368. https://doi .org/10.1177/2F1464884904044941

Pond, P., \& Lewis, J. (2019). Riots and Twitter: Connective politics, social media and framing discourses in the digital public sphere. Information, Communication \& Society, 22, 213-231. https://doi.org/10.1080/1369118X.2017.1366539

Reese, S. D., \& Buckalew, B. (1995). The militarism of local television: The routine framing of the Persian Gulf War. Critical Studies in Mass Communication, 12, 40-59. https://doi.org/10.1080/15295039509366918

Scheufele, D. A. (1999). Framing as a theory of media effects. Journal of Communication, 49, 103-122. https://doi.org/10.1111/j.146o-2466.1999.tbo2784.x

Schmitz, M. F., Filippone, P., \& Edelman, E. M. (2003). Social representations of attention deficit/hyperactivity disorder, 1988-1997. Culture and Psychology, 9, 383-406. https://doi.org/10.1177/2F1354067X0394004

Schultz, F., Utz, S., \& Göritz, A. (2011). Is the medium the message? Perceptions of and reactions to crisis communication via Twitter, blogs and traditional media. Public Relations Review, 37(1), 20-27. https://doi.org/10.1016/j .pubrev.2010.12.001

Semetko, H. A., \& Valkenburg, P. M. (2000). Framing European politics: A content analysis of press and television news. Journal of Communication, 50, 93-109. https://doi.org/10.1111/j.1460-2466.200o.tbo2843.x

Shoemaker, P. J., \& Reese, S. D. (1996). Mediating the message. White Plains, NY: Longman.

Simon, A., \& Xenos, M. (2000). Media framing and effective public deliberation. Political Communication, 17, 363-376. https://doi.org/10.1080 /10584600050178979

Snow, D. A., \& Benford, R. D. (1992). Master frames and cycles of protest. In 
A. D. Morris \& C. M. Mueller (Eds.), Frontiers in social movement theory (pp. 133-154). New Haven, CT: Yale University Press.

Spence, P. R., Sellnow-Richmond, D. D., Sellnow, T. L., \& Lachlan, K. A. (2016). Social media and corporate reputation during crises: The viability of video-sharing websites for providing counter-messages to traditional broadcast news. Journal of Applied Communication Research, 44, 199-215. https://doi.org/10.1080/oo909882.2016.1192289

Stevenson, R. L., \& Cole, R. R. (1984). Issues in foreign news. In R. L. Stevenson \& D. L. Shaw (Eds.), Foreign news and the new world information order (pp. 5-20). Iowa City, IA: Iowa State University Press.

Swanson, D. L. (2000). The homologous evolution of political communication and civic engagement: Good news, bad news, and no news. Political Communication, 17, 409-414. https://doi.org/10.1080/10584600050179031 Triggs, R. (2016, November). State of the smartphone industry 2016. Android Authority. Retrieved from https://www.androidauthority.com/state-of-the -smartphone-industry-q1-2016-713340/

Utz, S., Schultz, F., \& Glocka, S. (2013). Crisis communication online: How medium, crisis type and emotions affected public reactions in the Fukushima Daiichi nuclear disaster. Public Relations Review, 39, 40-46. https:// doi.org/10.1016/j.pubrev.2012.09.010

Valentini, C., \& Romenti, S. (2011). The press and Alitalia's 2008 crisis: Issues, tones and frames. Public Relations Review, 37, 360-365. https://doi .org/10.1016/j.pubrev.2011.07.002

Valenzuela, S., Piña, M., \& Ramírez, J. (2017). Behavioral effects of framing on social media users: How conflict, economic, human interest, and morality frames drive news sharing. Journal of Communication, 67, 803-826. https:// doi.org/10.1111/jcom.12325

Valenzuela, S., Puente, S., \& Flores, P. M. (2017). Comparing disaster news on Twitter and television: An intermedia agenda setting perspective. Journal of Broadcasting \& Electronic Media, 61, 615-637. https://doi.org/10.1080 /o8838151.2017.1344673

van der Meer, T., \& Verhoeven, P. (2013). Public framing organizational crisis situations: Social media versus news media. Public Relations Review, 39, 229-231. https://doi.org/10.1016/j.pubrev.2012.12.001

Wasike, B. S. (2013). Framing news in 140 characters: How social media editors frame the news and interact with audiences via Twitter. Global Media Journal, 6, 5-23. Retrieved from ProQuest database. 
Weiner, B. (1993). On sin versus sickness: A theory of perceived responsibility and social motivation. American Psychologist, 48, 957-965. https://doi .org/10.1037/0003-066X.48.9.957

Weiner, D. (2006, March/April). Crisis communications: Managing corporate reputation in the court of public opinion. Ivey Business Journal, pp. 1-6. Retrieved from https://iveybusinessjournal.com/publication/crisis -communications-managing-corporate-reputation-in-the-court-of-public -opinion/

Worldwide smartphone sales grew 3.9 percent in first quarter of 2016. (2016, May 19). Gartner. Retrieved from https://www.gartner.com/en/newsroom /press-releases/2016-05-19-gartner-says-worldwide-smartphone-sales -grew-4-percent-in-first-quarter-of-2016

$\mathrm{Wu}, \mathrm{H}$. D. (2000). Systemic determinants of international news coverage: A comparison of 38 countries. Journal of Communication, 50, 110-130. https:// doi.org/10.1111/j.1460-2466.200o.tbo2844.X

Yan, Y., \& Kim, Y. (2015). Framing the crisis by one's seat: A comparative study of newspaper frames of the Asiana crash in the USA, Korea, and China. Asian Journal of Communication, 25, 486-506. https://doi.org/10.1080/o 1292986.2014.990470

Zheng, B., Liu, H., \& Davison, R. M. (2018). Exploring the relationship between corporate reputation and the public's crisis communication on social media. Public Relations Review, 44, 56-64. https://doi.org/10.1016/j .pubrev.2017.12.006 